\title{
A Template for Success: Celebrating the Work of Judith Grabiner
}

\section{Della Dumbaugh and Adrian Rice}

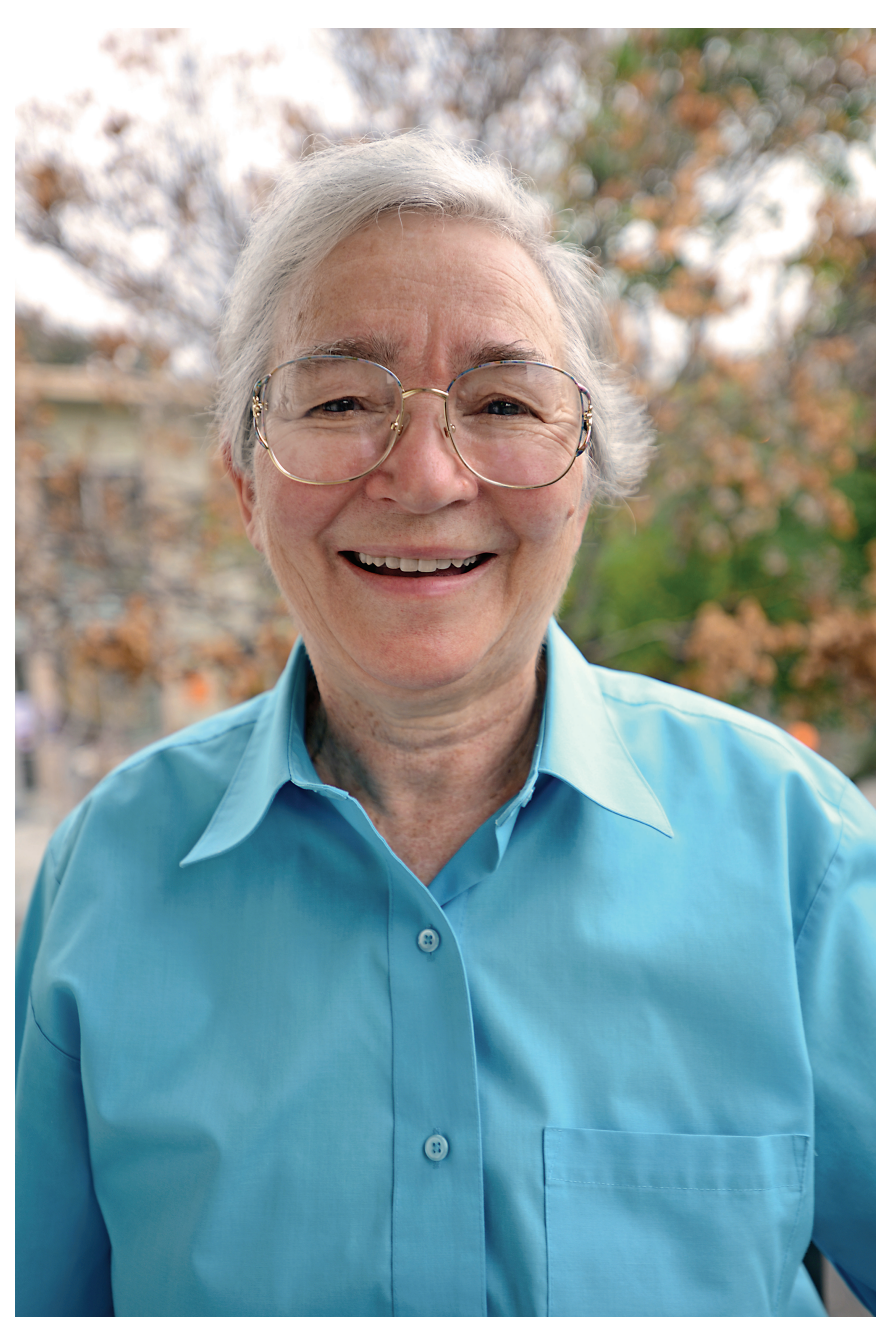

Della Dumbaugh is a professor of mathematics at the University of Richmond and an associate editor of the Notices. Her email address is ddumbaugh arichmond.edu.

Adrian Rice is a professor of mathematics at Randolph-Macon College. His email address is arice4@rmc.edu.

For permission to reprint this article, please contact:

reprint-permission@ams.org.

DOI: https://doi.org/10.1090/noti2035

\section{Introduction}

Judith Grabiner is a mathematician who specializes in the history of mathematics. She is currently the Flora Sanborn Pitzer Professor Emerita of Mathematics at Pitzer College, one of the Claremont Colleges in Claremont, California. She has authored more than forty articles, as well as three books: The Origins of Cauchy's Rigorous Calculus (1981), The Calculus as Algebra: J.-L. Lagrange, 1736-1813 (1990), and A Historian Looks Back: The Calculus as Algebra and Selected Writings (2010), which won the Beckenbach Prize from the Mathematical Association of America in 2014. She delivered an invited address titled "The Centrality of Mathematics in the History of Western Thought" at the International Congress of Mathematicians (Berkeley) in 1986. She is the only four-time winner-in 1984, 1998, 2005, and 2010of the Paul R. Halmos-Lester R. Ford Award for articles of expository excellence published in the American Mathematical Monthly. ${ }^{1}$ She has also received the Carl B. Allendoerfer Award for expository excellence in Mathematics Magazine on three occasions: in 1984, 1988, and 1996. In 2003 she was given the Mathematical Association of America's Deborah and Franklin Tepper Haimo Award for Distinguished College or University Teaching, and in 2013 she became an inaugural Fellow of the American Mathematical Society. This article explores her professional life and her farreaching contributions to the mathematical community.

\section{Scholarly Training}

In 1956 the strong mathematics program at the University of Chicago attracted Judith Victor (later Grabiner) to enroll as a first-year undergraduate. There she took "the world's greatest first-year calculus course," where Saunders Mac Lane lectured once a week on the foundations of the subject and an instructor met with the class at other times [4]. "It was an incredibly exciting way to learn calculus," Grabiner later recalled. While at Chicago she also took a class titled Organization, Methods and Principles of Knowledge,

${ }^{1}$ The MAA changed the name of the Lester R. Ford Award to the Paul $R$. Halmos-Lester R. Ford award in 2012. We have adopted the current award designation in this article. 
a special section of the University of Chicago's great books course designed for science students and taught by the physicist Aaron Sayvetz. She read Isaac Newton and Christiaan Huygens under his guidance and gained insights into logic as a philosophical idea. She took a physics class with the biophysicist John R. Platt, whose interests included the philosophy of science, vision, and perception. She also found "the best teacher I ever had in my life" in Herman Sinaiko, who taught her Humanities 3 course. She and her classmates referred to him as "Socrates"; from him she learned that philosophy and literature could be taught with the same rigor and robustness as mathematics. Humanities 3 served as a "turning point" for Grabiner. That experience helped her realize that her intellectual approach to the world after that would not only include mathematics but also history, philosophy, and literature [20].

Fortunately for Grabiner, a friend had a copy of the Harvard catalogue, where she noticed a program in the History of Science and Learning. George Sarton, regarded as the father of the history of science in America, had started the program in 1936, under which his student I. Bernard Cohen earned the first $\mathrm{PhD}$ in the history of science in America eleven years later. Cohen became Grabiner's thesis advisor and the first chair of the Department of the History of Science when it was formed at Harvard in $1966 .{ }^{2}$ He was known for pursuing several projects at once and, in particular, a large project on Newton in the years preceding and during Grabiner's arrival at Harvard. She read Newton's Principia in her first-year graduate seminar. Perhaps not surprisingly, then, Grabiner turned her attention to the history of calculus in her dissertation, writing, in particular, on the work of Lagrange. From Cohen she learned "scholarship as a vocation." As she expressed it to him on the occasion of his retirement:

Listening to you in seminars, watching you as your research assistant, reading your papers-all together conveyed to me the meaning of scholarship as a vocation, so that when I read Max Weber's "Wissenschaft als Berufung" in my first year of graduate school I knew exactly what he was talking about. And-as I said in the preface to my Cauchy book-you taught me to think like a historian.... I find it hard to believe that you are retiring, and impossible to imagine the teaching of the history of science in the United States without you. But of course, it won't be without you. Every time

${ }^{2}$ The Harvard faculty voted to start a graduate program in the history of science in 1936. It was not immediately developed, however, in part because it would be "unconscionable to prepare students for a field in which there was virtually no hope of finding a position" [10, p. 19]. Following World War II, the launch of Sputnik, and the general expansion of American college and university faculty positions, the history of science gained momentum, and the department was officially formed in 1966. one of your former students lectures on Newton, leads a discussion on Aristotle, thinks about the way scientific thought has changed, you're there. [Grabiner to Cohen, Dec. 19, 1983, as quoted in [10, footnote 89]]

She credits Dr. Uta C. Merzbach (1933-2017), an advanced graduate student in history of mathematics when Grabiner came to Harvard and later the first curator of mathematical instruments at the Smithsonian Institution and author of, among other works, Dirichlet: A Mathematical Biography (Birkhaüser, 2018), as a strong female role model, as well as being a mentor, intellectual guide, and valued friend.

The influence of her second thesis advisor, Dirk J. Struik of MIT, is also everywhere present in Grabiner's work, particularly in her use of his quintessential Source Book in Mathematics, 1200-1800, an oft-cited source in her publications. She admired his high standards and scholarly expertise, his strong commitment to ethical and social concerns, and his observation "that a mathematician remains a social being even when studying lines in hypercones in 7 dimensional space" [3], and she vibrantly wove them into the tapestry of her own work.

In her dissertation, "The Calculus as Algebra: J.-L. Lagrange, 1736-1813," she explored the mathematical practices of Lagrange to understand the origins of the rigorous analysis of the calculus by Augustin-Louis Cauchy, Bernhard Bolzano, and Karl Weierstrass. For Lagrange the calculus was not about rates of change, ratios of differentials, or even what was then understood as a limit. For Lagrange the calculus was about algebra, specifically about the algebraic analysis of finite quantities. He did not view derivatives in terms of deltas and epsilons but, rather, in terms of what he thought of as the algebra of infinite series. In particular, he defined the derivative of $f(x)$ as the coefficient of the linear term of the power-series expansion of $f(x+h)$. Consequently, Lagrange's work was often seen as a step backward in the development of calculus. Grabiner redirects this view by showing that this "older view of Lagrange's calculus is wrong" [13, p. 3]. Lagrange emphasized that the derivative is a function and used the algebra of inequalities to prove theorems about derivatives and integrals. So Bolzano and Cauchy's efforts to rigorize the calculus both depended on Lagrange, a fact which, in Grabiner's words, "magnifies his importance" [13, p. 4].

\section{Overview of Work}

Within a decade of earning her PhD, in 1974 Grabiner found herself at a special American Academy of Arts and Sciences (Cambridge, MA) workshop with "leading contemporary experts" in mathematics and the history of mathematics. The workshop participants included Garrett Birkhoff, George Mackey, Alan Tucker, and Felix Browder 
among the mathematicians, and Bernard Cohen, Kenneth May, Thomas Hawkins, Morris Kline, Albert Lewis, and Carl Boyer among the historians. On this occasion, she gave a talk titled "The Mathematician, the Historian and the History of Mathematics." With this distinguished audience of mathematicians and historians, she considered the different questions they bring to the table when they consider mathematics. In particular, she noted that mathematicians are often interested in "the past as part of the present," while historians of mathematics view the present as laden with "many and diverse relics from the past and as the end of long, complex processes" [16, p. 440]. ${ }^{3}$ She also underscored the value of the history of mathematics for its contributions to human culture and its role in the teaching and understanding of mathematics. This inextricable link between research in the history of mathematics and its helpful presence in the classroom remained a constant in Grabiner's work over the course of her career.

This observation leads naturally to four themes that emerge when considering the whole of Grabiner's work. (1) First and foremost, there is her deep erudition, founded on her training as a mathematician and as a historian of science, firmly embedded in a liberal arts tradition that also encompasses the history of art, literature, and philosophy. For example, her celebrated paper asking "Why did Lagrange 'prove' the parallel postulate?" features the work of artists Piero della Francesca, Leonardo da Vinci, and Raphael in her discussion of perspective. (2) Although her name is most often associated with Cauchy, it is her work on Lagrange, and the eighteenth century in particular, that forms the bedrock of her scholarship. With Lagrange as a focal point, she moved forward to Cauchy and backwards to Colin Maclaurin and Leonhard Euler, giving her a deep understanding of the creation of the calculus over more than 150 years, which she shares in many publications and leverages in the classroom. (3) The concept of change is everywhere present in her work as a scholar. There is the obvious language of change in her studies of the calculus, but we mean something much more than

\footnotetext{
${ }^{3}$ For a complete list of workshop participants and an overview of the workshop, including who participated in the discussions following talks, see [7, pp. 1625]. In particular, following introductory remarks by the organizers, Grabiner gave the first talk of the workshop, and Jean Dieudonné, J. P. Kahane, Alberto Dou, Hilary Putnam, and George Mackey participated in the discussion. Grabiner's published version of the talk, "The Mathematician, the Historian and the History of Mathematics," in Historia Mathematica 2 (1975), 439-447, includes details of the discussion, particularly Dieudonné's comments and Grabiner's responses to them. The discussion of her paper also mentions that George Mackey "expressed interest in history, but felt that because of the pressures of his discipline, he could not be interested in too detailed a history" [p. 447]. For more on Mackey, including some mini-histories of mathematics he offered in his correspondence, see Della Dumbaugh, "Extensive cooperation with rugged individualism: George Mackey's guide for practitioners of mathematics," Notices Amer. Math. Soc. 66 (June/Julv 2019), 883-891, https://www.ams.org /journals/notices/201906/rnoti-p883.pdf
}

the mathematics of calculus. It is her understanding of how viewpoints, including her own, change over time. She regularly encourages her readers to put themselves in the mindset of the scholars she discusses. When considering the progress of calculus throughout the eighteenth century, for example, she reminds her readers that the guiding question was to produce mathematical results, not to build a foundation for calculus. Consequently, it is "unfair" to criticize Euler and others for what more modern mathematicians would call a "lack of rigor" [17, p. 187]. (4) Finally, she is a brilliant expositor. Her numerous Halmos-Ford and Allendoerfer awards, combined with her Beckenbach Book Prize, testify to her expository excellence. But these external validations are no substitute for sitting down with one of her articles and reveling in the compelling questions she motivates and poses at the beginning, her plan for addressing them, the strategy she follows to accomplish her goal, and the conclusion she reaches that inevitably ties up the work with the equivalent of a beautiful bow. She is a master of her craft.

By way of an example, which, incidentally, is how Grabiner often guides her readers, let us consider her discussion of an eighteenth-century proof in her award-winning "Who gave you the epsilon? Cauchy and the origins of rigorous calculus." To illustrate how mathematicians made important discoveries in their efforts to find results rather than to explore rigorous foundations, she offers Euler's 1734 solution to the famous "Basel problem" of finding the precise value of the sum of the reciprocals of the squares of the natural numbers:

$$
1+\frac{1}{4}+\frac{1}{9}+\cdots+\frac{1}{k^{2}}+\cdots
$$

Grabiner writes:

It clearly has a finite sum since it is bounded above by the series

$$
1+\frac{1}{1 \cdot 2}+\frac{1}{2 \cdot 3}+\frac{1}{3 \cdot 4}+\cdots \frac{1}{(k-1) \cdot k}+\cdots
$$

whose sum was known to be 2 ; Johann Bernoulli had found this sum by treating $\frac{1}{1 \cdot 2}+\frac{1}{2 \cdot 3}+\frac{1}{3 \cdot 4}+\cdots$ as the difference between the series $\frac{1}{1}+\frac{1}{2}+\frac{1}{3}+\cdots$ and the series $\frac{1}{2}+\frac{1}{3}+\frac{1}{4}+\cdots$, and observing that this difference telescopes.

Euler's summation of $\sum_{k=1}^{\infty} \frac{1}{k^{2}}$ makes use of a lemma from the theory of equations: given a polynomial equation whose constant term is one, the coefficient of the linear term is the $\mathrm{sum}^{4}$ of the reciprocals of the roots with the signs changed. This result was both discovered and demonstrated by

\footnotetext{
${ }^{4}$ The original article says "product" here [17, p. 187]. This typo is corrected in [6, p. 6].
} 
considering the equation $(x-a)(x-b)=0$, having roots $a$ and $b$. Multiplying and then dividing out $a b$, we obtain

$$
\left(\frac{1}{a b}\right) x^{2}-\left(\frac{1}{a}+\frac{1}{b}\right) x+1=0
$$

the result is now obvious, as is the extension to equations of higher degree.

Euler's solution then considers the equation $\sin x=0$.

Expanding this as an infinite series, Euler obtained

$$
x-\frac{x^{3}}{3 !}+\frac{x^{5}}{5 !}-\cdots=0 .
$$

Dividing by $x$ yields

$$
1-\frac{x^{2}}{3 !}+\frac{x^{4}}{5 !}-\cdots=0
$$

Finally, substituting $x^{2}=u$ produces

$$
1-\frac{u}{3 !}+\frac{u^{2}}{5 !}-\cdots=0
$$

But Euler thought that power series could be manipulated just like polynomials. Thus, we now have a polynomial equation in $u$, whose constant term is one. Applying the lemma to it, the coefficient of the linear term with the sign changed is $\frac{1}{3 !}=\frac{1}{6}$. The roots of the equation in $u$ are the roots of $\sin x=0$ with the substitution $u=x^{2}$, namely $\pi^{2}, 4 \pi^{2}, 9 \pi^{2}, \ldots$ Thus the lemma implies

$$
\frac{1}{6}=\frac{1}{\pi^{2}}+\frac{1}{4 \pi^{2}}+\frac{1}{9 \pi^{2}}+\cdots
$$

Multiplying by $\pi^{2}$ yields the sum of the original series

$$
\frac{1}{1}+\frac{1}{4}+\frac{1}{9}+\cdots+\frac{1}{k^{2}}+\cdots=\frac{\pi^{2}}{6}
$$

[17, p. 187].

Following this presentation of Euler's proof, Grabiner seems to know the mind of her more modern reader. She encourages a broader view of Euler's result, one that takes into account the priorities of the eighteenth century while acknowledging current mathematical conventions. In particular, since for Euler and his contemporaries the emphasis was on obtaining mathematical results rather than answering questions about foundations, she argues that mathematicians were free to make these types of "important new discoveries" without the procedural strictures of today's more rigorous analysis.

As Grabiner noted, Cauchy would later prove the same result by "calculating the difference between the $n$th partial sum and $\frac{\pi^{2}}{6}$ and showing that it was arbitrarily small" [17, p. 193]. Let the present authors expand on Grabiner's brief remark so that the reader can see, by contrasting Euler's proof with the detail provided by Cauchy in his Cours $d^{\prime}$ analyse (1821), how much more attention was given to matters of convergence some eighty-seven years later. Starting with an expression

$$
\frac{(m+2)(m-2)}{3 !}=\frac{1}{\sin ^{2} \frac{2 \pi}{2 m}}+\frac{1}{\sin ^{2} \frac{4 \pi}{2 m}}+\cdots+\frac{1}{\sin ^{2} \frac{(m-2) \pi}{2 m}}
$$

derived from standard trigonometric identities, where $m$ is a positive even integer, Cauchy multiplied through by $\left(\frac{\pi}{m}\right)^{2}$ to obtain

$$
\begin{aligned}
\frac{\pi^{2}}{6}\left(1-\frac{4}{m^{2}}\right)= & \frac{\left(\frac{\pi}{m}\right)^{2}}{\sin ^{2} \frac{\pi}{m}}+\frac{1}{4} \frac{\left(\frac{2 \pi}{m}\right)^{2}}{\sin ^{2} \frac{2 \pi}{m}}+\frac{1}{9} \frac{\left(\frac{3 \pi}{m}\right)^{2}}{\sin ^{2} \frac{3 \pi}{m}} \\
& +\cdots+\frac{1}{\left(\frac{m}{2}-1\right)^{2}} \frac{\left(\frac{(m-2) \pi}{2 m}\right)^{2}}{\sin ^{2} \frac{(m-2) \pi}{2 m}}
\end{aligned}
$$

or

$$
\frac{\pi^{2}}{6}\left(1-\frac{4}{m^{2}}\right)=\sum_{k=1}^{n} \frac{1}{k^{2}} \frac{\left(\frac{k \pi}{m}\right)^{2}}{\sin ^{2} \frac{k \pi}{m}}+\sum_{k=n+1}^{\frac{m}{2}-1} \frac{1}{k^{2}} \frac{\left(\frac{k \pi}{m}\right)^{2}}{\sin ^{2} \frac{k \pi}{m}},
$$

where $n$ is a positive integer less than $\frac{m}{2}$. Cauchy claimed that for any two collections of numbers, $a, b, c, \ldots, n$ and $a^{\prime}, b^{\prime}, c^{\prime}, \ldots, n^{\prime}$, there always exists a constant, denoted $M(a, b, c, \ldots, n){ }^{5}$ such that

$$
\begin{aligned}
a^{\prime} a+b^{\prime} b & +c^{\prime} c+\cdots+n^{\prime} n \\
& =\left(a^{\prime}+b^{\prime}+c^{\prime}+\cdots+n^{\prime}\right) \cdot M(a, b, c, \ldots, n),
\end{aligned}
$$

which, since

$$
1<\frac{x}{\sin x}<\frac{1}{\cos x}
$$

allowed him to express the first sum on the right-hand side of (1) as

$$
\left(1+\frac{1}{4}+\frac{1}{9}+\cdots+\frac{1}{n^{2}}\right) \cdot M\left(1, \frac{1}{\cos ^{2} \frac{n \pi}{m}}\right) .
$$

Similarly, since for positive $x<\frac{\pi}{2}$,

$$
\frac{x}{\sin x}<\frac{\frac{1}{2} x}{\sin \frac{1}{2} x} \frac{1}{\cos \frac{1}{2} x}<\frac{1}{\cos ^{2} \frac{1}{2} x}<\frac{1}{\cos ^{2} \frac{\pi}{4}}=2,
$$

every term in the second sum of (1) is strictly less than $\frac{4}{n^{2}}$, leading to that sum being bounded by 0 and $\frac{2 m}{n^{2}}$. Cauchy

${ }^{5}$ Cauchy referred to this constant as "moyenne" even though, in general, it need not be the arithmetic mean. [8, p. 14] translates "moyenne" as "average." See also [9, pp. 28-29]. 
could thus rewrite equation (1) as

$$
\begin{aligned}
\frac{\pi^{2}}{6}\left(1-\frac{4}{m^{2}}\right)=\left(1+\frac{1}{4}+\frac{1}{9}+\cdots+\frac{1}{n^{2}}\right) \\
\cdot M\left(1, \frac{1}{\cos ^{2} \frac{n \pi}{m}}\right)+\frac{2 m}{n^{2}} \cdot M(0,1)
\end{aligned}
$$

or, rearranging, as

$$
\begin{aligned}
1 & +\frac{1}{4}+\frac{1}{9}+\cdots+\frac{1}{n^{2}} \\
& =\frac{\pi^{2}}{6}\left(1-\frac{4}{m^{2}}\right) \cdot M\left(1, \cos ^{2} \frac{n \pi}{m}\right)-\frac{2 m}{n^{2}} \cdot M(0,1) .
\end{aligned}
$$

Remembering that $\frac{1}{2} m>n$, pushing $n$ to infinity produced the required infinite series on the left-hand side while giving the limit of zero for $4 / \mathrm{m}^{2}$ on the right. One final condition was needed to obtain limits for $n \pi / m$ and $2 m / n^{2}$, although Cauchy's explanation is less than satisfactory by modern standards: "It is easy to see that if we always take for $\frac{1}{2} m$ the smallest of the integers greater than $n^{a}$ (where $a$ denotes a number contained between 1 and 2), the ratios $\frac{n}{m}$ and $\frac{m}{n^{2}}$ converge together, for increasing values of $n$, towards the limit zero" [8, p. 383]. Thus, Cauchy concluded, the right-hand side of (2) converges to the limit of $\pi^{2} / 6{ }^{6}$

Grabiner was well aware of what happened in the intervening decades between these proofs of Euler and Cauchy. She captured many of these ideas in her The Origins of Cauchy's Rigorous Calculus. Here, however, as elsewhere in her work, we are reminded to take into consideration the long journey of the calculus from Newton and Leibniz to Cauchy, especially as it relates to the students in our calculus classrooms. As she put it in "The changing concept of change: The derivative from Fermat to Weierstrass":

The real historical development of mathematicsthe order of discovery-reveals the creative mathematician at work, and it is creation that makes doing mathematics so exciting. The order of exposition, on the other hand, is what gives mathematics its characteristic logical structure and its incomparable deductive certainty. Unfortunately, once the classic exposition has been given, the order of discovery is often forgotten. The task of the historian is to recapture the order of discovery: not as we think it might have been, not as we think it should have been, but as it really was. [15, p. 206]

This is to say that students benefit from understanding the process of the development of mathematics and, in this case, the calculus. Grabiner's celebration of Euler's proof (and Lagrange's approach in viewing calculus from

\footnotetext{
${ }^{6}$ These details are taken from [9, pp. 455-457, 556-559]. For an English translation, see [8, pp. 381-383].
}

an algebraic perspective, for that matter) encourages students to realize that they can understand the epsilon-delta foundations of calculus simply by recognizing that they don't have to start there. They can start with Euler and be in very good company.

We cannot leave this discussion of "Who gave you the epsilon?" without calling attention to its brilliant conclusion. By the time readers reach the final pages of this work, they may have lost track of the title. But not Grabiner. To underscore her enduring point of considering the rigorous form of calculus as a "completed whole" of the work of many mathematicians over more than 150 years, she offers the epsilon (literally!) as a tangible reminder. "In Cauchy's work," she asserts, "one trace indeed was left of the origin of rigorous calculus in approximation-the letter epsilon. The $\epsilon$ corresponds to the initial letter in the word 'erreur' (or 'error'), and Cauchy in fact used $\epsilon$ for 'error' in some of his work on probability. It is both amusing and historically appropriate that the ' $\epsilon$, once used to designate the 'error' in approximations, has become transformed into the characteristic symbol of precision and rigor in the calculus. As Cauchy transformed the algebra of inequalities from a tool of approximation to a tool of rigor, so he transformed the calculus from a powerful method of generating results to the rigorous subject we know today" [17, p. 193].

But Grabiner does not just encourage a "whole" view of mathematics for the sake of the discipline: she also encourages a view of mathematics as part of the whole history of ideas. In her 1986 International Congress address in Berkeley, California, Grabiner chose the topic "The Centrality of Mathematics in the History of Western Thought." She began with a student and a teaching experience, another reflection of the strong link between the history of mathematics and teaching. In particular, she aimed to "recapture" the critical and beautiful moment when a student read Euclid's Elements of Geometry and exclaimed, "I never realized mathematics was like this. Why, it's like philosophy!" [14, p. 220]. She discussed "major developments in the history of ideas" where mathematics played a key role. Among them, she highlighted the role of Euclidean thinking in the Declaration of Independence of the United States. This foundational document

... is one more example of an argument whose authors tried to inspire faith in its certainty by using the Euclidean form. "We hold these truths to be self-evident..." not that all right angles are equal, but "that all men are created equal." These self-evident truths include that if any government does not obey these postulates, "it is the right of the people to alter or abolish it." The central section begins by saying that they will "prove" King George's government does not obey them. The conclusion is, "We, therefore... declare, that these 
United Colonies are, and of right ought to be, free and independent states." [14, p. 221, Grabiner's emphasis]

Here, we find Grabiner at her best. She artfully reminds us of the presence of mathematics in our everyday lives, in this case with the very words and ideas that built America.

In the ICM paper Grabiner also highlighted René Descartes's outline for how to make discoveries. In his 1637 Discourse on Method, Descartes outlined his analytical approach: (1) analyze the whole into the correct "elements" from which truths could be later deduced, (2) divide each of the "difficulties" into as many parts as possible and as might be necessary for an easier solution, and (3) start with the things that were simplest and easiest to understand and move toward more complex knowledge [14, p. 223]. In his 1776 Wealth of Nations, Adam Smith drew from this philosophical work of Descartes to use the concept of the division of labor to analyze the competitive success of economic systems. Grabiner traces the influence of Smith's work on others, including Gaspard Francois de Prony and his organization of people to carry out calculations according to a hierarchical structure, with planners reducing complex calculations to simple additions and subtractions carried out by lower-level human "calculators." Charles Babbage later "applied the Smith-Prony analysis and embodied it in a machine" [14, p. 223].

But she also drew attention to the less favorable views of mathematics, which she called "attacks" on the discipline, since these form a part of the history of ideas as well. She cites as an example Walt Whitman's distaste for a lecture on celestial distances as conveyed in his poem "When I Heard the Learn'd Astronomer." There, as Whitman put it, he became "tired and sick" and went outside to look "up in perfect silence at the stars" [14, p. 228]. She also refers to the work of Charles Dickens, among others, and his use of mathematics as a dehumanizing force in his 1854 novel Hard Times.

Still, Grabiner argues, what matters is not whether the mathematics is used for good or ill, but rather that mathematics has played an essential role in the history of ideas and thought. She concluded this key lecture (and associated article) by advocating that those charged with teaching mathematics not only focus on quantitative or logical reasoning but also on its proper role in fully understanding "the humanities, the sciences, the world of work, and the world of man" [14, p. 229].

Teaching: Teleological showmanship. Grabiner learned a great deal about teaching from her advisor at Harvard, I. Bernard Cohen. In particular, while taking his survey course as a graduate student, she came to realize that "good teaching is teleological showmanship." She also credited Cohen for inspiration about how "to make scientific ideas live" and identified Cohen and his wife, Frances, as "exemplars of the way to treat students as people" [Grabiner to Cohen, December 19, 1983, as quoted in [10, p. 32]]. What she meant by this is further explained by one of her former students at Harvard:

Bernard and his wife Frances always welcomed graduate students into their home, not just as fledgling scholars but as independent thinkers in their own right. Frances, as a former reporter covering the Spanish Civil War, was tenacious in grilling Bernard's students at cocktails and dinner parties on everything from ancient history to current politics. It was also a place where Bernard's students could meet, informally, noted figures of the history of science like Marie Boas and A. Rupert Hall, D. T. Whiteside, and Bartel van der Waerden, for example, all of whom I recall meeting at the Cohens' at one time or another; Judy recently told me that she too valued such encounters, in particular having met Sir Eric Ashby through the Cohens.

"Teleological showmanship" is another matter, and that we all learned from Bernard in the classroom. There could have been no better example of that than his "last lecture" at Harvard on the occasion of his retirement. It is a tradition at Harvard that distinguished retiring faculty give a "last lecture," and in Bernard's case, former students from all parts of the world returned to Cambridge to watch a spectacular performance, a lecture that ended with a string quartet playing the "alchemical music" Michael Maier had included in his seventeenth-century alchemical treatise, Atalanta Fugiens, while a thermite experiment was conducted that ended with an appropriate explosion; one fully expected Bernard to exit the lecture hall on a cart propelled with a fire extinguisher that he (infamously) used in his Nat Sci 3 course to demonstrate Newton's third law of motion.

In Judy's case, the teleology was omnipresent. Whenever she spoke about history of science, including history of mathematics, she always had a purpose in mind-to be engaging, to reveal the true interest in whatever she was discussing, and to make it relevant. That is the secret to good teaching that Bernard had embodied in his own teaching and that she had also mastered, par excellence.

Sometimes the teleology was combined with her equally impressive concern for students as people-especially beleaguered graduate students! I will always remember the many sessions she spent with me and Wilbur Knorr, another graduate student in history of science whom Judy was also preparing for our oral examinations in history 
of modern mathematics at the end of our second year at Harvard. The day before my exam, I was walking home from Widener Library with a pile of books under my arm intending to review a few last details, when the route I was taking happened to pass by the Grabiners' house, where Judy was on the porch with their recently-born son David, enjoying the fading sun on a late balmy day in May. "Where are you going with all those books?" she asked-and no sooner had I explained where I was headed than she insisted: "No you're not-you know more than enough for tomorrow, and those books aren't going to help." She invited me onto the porch, and soon her husband Sandy appeared and offered me a cold beer, and we chatted for a while until Judy suggested I go home, forget the books, and get a good night's sleep. That was probably the best advice before a qualifying exam that any graduate student could possibly have been given-along with the cold beer! [2]

While Cohen may have been a model of excellent teaching for Grabiner, she ultimately had to find her own style. Grabiner's research informed her teaching, and her teaching informed her research. It was not uncommon for Grabiner to motivate an article in the history of mathematics with a teaching anecdote. In "The changing concept of change: The derivative from Fermat to Weierstrass," for example, her opening paragraph grabs the reader's attention:

Some years ago while teaching the history of mathematics, I asked my students to read a discussion of maxima and minima by the seventeenthcentury mathematician, Pierre Fermat. To start the discussion, I asked them, "Would you please define a relative maximum?" They told me it was a place where the derivative was zero. "If that's so," I asked, "then what is the definition of a relative minimum?" They told me, that's a place where the derivative is zero. "Well, in that case," I asked, "what is the difference between a maximum and a minimum?" They replied that in the case of a maximum, the second derivative is negative. What can we learn from this apparent victory of calculus over common sense? [15, p. 195]

According to Grabiner, these sorts of teaching anecdotes subsequently inspired her to reflect on aspects of her own research, including the historical development of the calculus. She frequently ends her articles imploring educators to remember the centuries involved in creating and codifying an idea and reflecting on what that means when students try to learn that idea in only a few minutes during a single class meeting. She asks, "Why does this matter?"
And she offers many answers, including ones generally related to teaching.

As early as her talk at the American Academy of Arts and Sciences workshop in 1974, Grabiner emphasized the pedagogical value of the history of mathematics. On that occasion, she identified three ways the history of mathematics helps in teaching and understanding mathematics. First, history helps teachers understand the "inherent difficulty" of a concept. Second, history helps students understand the genesis of an idea, and that often motivates them. Finally, historical background helps students and mathematicians understand how mathematics fits in with the whole of human thought [16, pp. 442-443]. ${ }^{7}$ One Pitzer student underscored the far-reaching impact of Grabiner's aims when she reflected on her experiences in Grabiner's class: "I took History of Math from Judy my second year at Pitzer....I absolutely loved History of Math. Everything that I learned in that class was new. Judy was passionate about her teaching, bringing her enthusiasm every day to lecture. I greatly enjoyed her style of teaching, the ease that she had with the students as well as the material. I use what I learned in her class to this day with my own students. I find that my high schoolers can get more out of their classes once they know a little of the history behind the concept/name/idea/etc. Thanks to Judy, I can share this knowledge with them." 8

For Grabiner, the classroom offered an opportunity for a shared experience, an exchange between individuals rather than a one-way conversation. And it was hardly limited to the physical boundary of a classroom. In her famed liberal arts courses on mathematics, "Mathematics, Philosophy, and the Real World" and "Mathematics in Many Cultures," she encouraged her students to recognize the pervasive presence of mathematics and celebrate it with their creativity and insights in their individual research projects. And then she celebrated their research projects. In her article "How to teach your own liberal arts mathematics course," she called attention to these projects born, as they were, at the intersection of mathematics and her students interests. These students pursued projects on the misuse of mathematics in movies, high-altitude cooking, baseball arbitration, and the Japanese Lottery, among other

\footnotetext{
${ }^{7}$ Sometimes that historical background leads to research in a new area. Leonard Dickson undertook what became his monumental History of the Theory of Numbers in order to understand the discipline. Dickson's most distinguished student, A. Adrian Albert, suggested that Dickson wrote his History of the Theory of Numbers to become more acquainted with number theory. "Dickson always said that mathematics is the queen of sciences," Albert asserted, "and that the theory of numbers is the queen of mathematics. He also stated that he had always wished to work in the theory of numbers and that he wrote his monumental History of the Theory of Numbers so that he could know all of the work which had been done in the subject" [5, p. 333].

${ }^{8}$ Quotation from a student, included in a private communication from David Bachman, professor of mathematics at Pitzer College, July 17, 2019.
} 
compelling topics [12, pp. 108-109, 113-114]. When she received the Deborah and Franklin Tepper Haimo Award for Distinguished College or University Teaching in 2003, in fact, Grabiner used the opportunity to thank these students in particular. As she put it, "I thank the students in my classes at Pitzer College, especially those from 'Mathematics in Many Cultures' and from 'Mathematics, Philosophy, and the Real World,' for the inspiration and ideas they have provided me. They've sustained my faith that everybody can understand and appreciate mathematics and its infinite uses, and the honor belongs to them." ${ }^{9}$ Her colleagues also recognized her important contributions to the institution. When Grabiner retired from Pitzer College in 2016, Gizem Karaali, professor of mathematics at Pomona College, celebrated Grabiner's influence and noted her ability to reach "students who would otherwise be unreachable, displaying effortlessly the impact of mathematics on the Western Civilization, and the human, the cultural, the social, the historical, and the philosophical dimensions of our discipline along with its immense power." Even though Grabiner has officially retired, you can still take her course "Mathematics, Philosophy, and the Real World" through the Teaching Company. ${ }^{10}$

\section{Concluding Thoughts}

In 2010 the Mathematical Association of America awarded Grabiner her fourth Halmos-Ford Award, this time for her paper "Why did Lagrange 'prove' the parallel postulate?" which appeared in the American Mathematical Monthly in January 2009. In celebrating the award, the president of Pitzer College, Laura Skandera Trombley, noted that "[g]enerations of Pitzer students have been fortunate to be a student of Professor Grabiner's, and it is utterly fitting that she be recognized for her excellence in scholarship." 11 Although Trombley limited this good fortune to Pitzer students, Grabiner's influence has extended far beyond that institution. In particular, at the very beginning of her career, Grabiner described the difficulties in store for any aspiring historian of mathematics. "The path for the historian of mathematics is difficult," Grabiner observed, because one requires not only "the historian's training, but also needs to know a great deal of mathematics. The history of science is itself a young and relatively small profession; the number of historians of mathematics, because of the types of knowledge needed, is even smaller. Still the need for such people is apparent" [16, p. 443]. She not only advocated for the profession with this template for success, but she also embraced these ideals in her own

${ }^{9}$ For the citation for the award and Grabiner's response, see https: //www . maa . org/sites/default/files/pdf/awards/2003-prizebook.pdf

${ }^{10}$ For details, see https://www. thegreatcourses.com/courses /mathematics-phi1osophy-and-the-rea1-world.htm1.

${ }^{11} \mathrm{See} \quad$ https://www.maa.org/news/math-news/judith-grabiner -wins-maas-ford-award-for-the-fourth-time. work. In this way, through her scholarship, her teaching, and her tireless coupling of the two, she has helped lead the way for a generation of historians of mathematics to follow.

\section{References}

[1] David Bachman to Della Dumbaugh, July 17, 2019.

[2] Joseph W. Dauben to Della Dumbaugh and Adrian Rice, August 5, 2019.

[3] Judith Grabiner to Della Dumbaugh, July 26, 2019.

[4] Judith Grabiner, phone interview, July 1, 2019.

[5] A. A. Albert, Leonard Eugene Dickson, 1874-1954, Bull. Amer. Math. Soc. 61 (1955), 331-345, DOI 10.1090/S0002-9904-1955-09937-3. MR70564

[6] Marlow Anderson, Victor Katz, and Robin Wilson (eds.), Who gave you the epsilon? and other tales of mathematical history, MAA Spectrum, Mathematical Association of America, Washington, DC, 2009. MR2605650

[7] Garrett Birkhoff (ed.), Proceedings of the American Academy Workshop on the Evolution of Modern Mathematics, Historia Math., vol. 2, University of Toronto Press, Toronto, Ont., 1975. Held at the American Academy of Arts and Sciences, Boston, Mass., Aug. 7-9, 1974; With a foreword by John Voss. MR0392303

[8] Robert E. Bradley and C. Edward Sandifer, Cauchy's Cours d'analyse: An annotated translation, Sources and Studies in the History of Mathematics and Physical Sciences, Springer, New York, 2009. MR2541811

[9] Augustin-Louis Cauchy, Cours d'analyse de l'École Royale Polytechnique. Première partie: Analyse algébrique, Instrumenta Rationis. Sources for the History of Logic in the Modern Age, VII, Cooperativa Libraria Universitaria Editrice Bologna, Bologna, 1992. Reprint of the 1821 edition; Edited and with an introduction by Umberto Bottazzini. MR1267567

[10] Joseph W. Dauben, Mary Louise Gleason, and George E. Smith, Seven decades of history of science. I. Bernard Cohen (1914-2003), second editor of Isis, Isis 100 (2009), no. 1, 435, DOI 10.1086/597575, MR2522721

[11] Judith V. Grabiner, A historian looks back: The calculus as algebra and selected writings, MAA Spectrum, Mathematical Association of America, Washington, DC, 2010. MR2724809

[12] Judith Grabiner, How to teach your own liberal arts mathematics course, Journal of Humanistic Mathematics 1 (January 2011), 101-118.

[13] Judith V. Grabiner, The calculus as algebra: J.-L. Lagrange, 1736-1813, Harvard Dissertations in the History of Science, Garland Publishing, Inc., New York, 1990. MR1098713

[14] Judith V. Grabiner, The centrality of mathematics in the history of Western thought, Math. Mag. 61 (1988), no. 4, 220230, DOI 10.2307/2689357. MR962583

[15] Judith V. Grabiner, The changing concept of change: the derivative from Fermat to Weierstrass, Math. Mag. 56 (1983), no. 4, 195-206, DOI $10.2307 / 2689807$, MR715218 


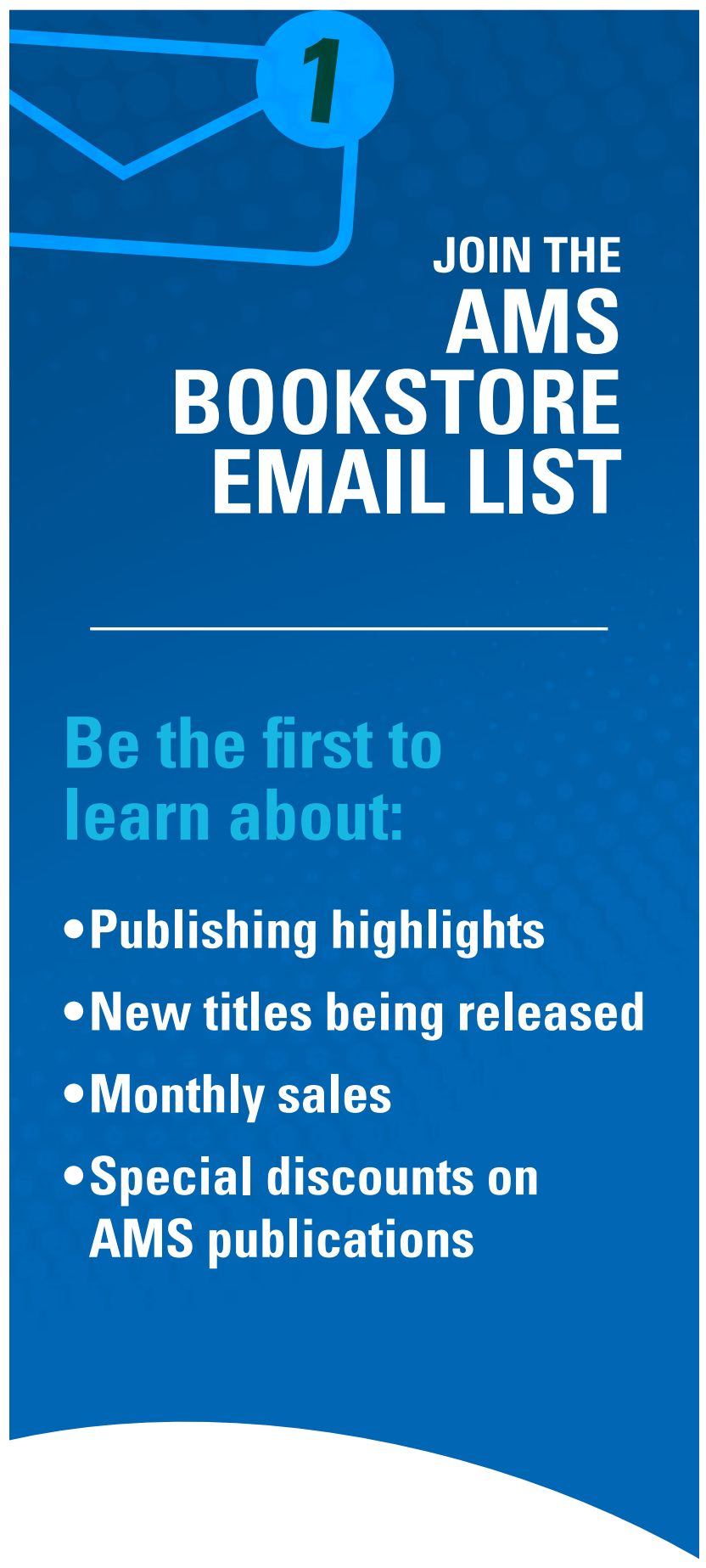

[16] Judith V. Grabiner, The mathematician, the historian, and the history of mathematics, Historia Math. 2 (1975), no. 4, 439-447, DOI 10.1016/0315-0860(75)90101-9 MR490837

[17] Judith V. Grabiner, Who gave you the epsilon? Cauchy and the origins of rigorous calculus, Amer. Math. Monthly 90 (1983), no. 3, 185-194, DOI 10.2307/2975545 MR691368

[18] Judith V. Grabiner, Why did Lagrange "prove" the parallel postulate?, Amer. Math. Monthly 116 (2009), no. 1, 3-18. MR2478750

[19] D. J. Struik (ed.), A source book in mathematics, 1200-1800, Princeton Paperbacks, Princeton University Press, Princeton, NJ, 1986. Reprint of the 1969 edition. MR858706

[20] Derek Tsang, Beauty in numbers: Mathematics historian Judith Victor Grabiner, $S B^{\prime} 60$, teaches math to the liberal arts masses, The University of Chicago Magazine (March-April 2014), https://mag . uchicago . edu /science-medicine/beauty-numbers.

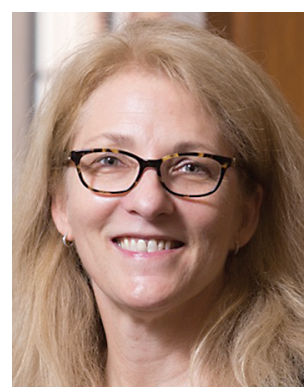

Della Dumbaugh

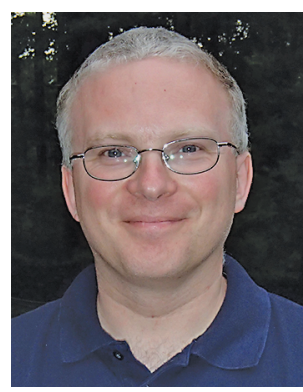

Adrian Rice

\section{Credits}

Photo of Grabiner is courtesy of Pitzer College.

Dumbaugh author photo is used by permission of the University of Richmond.

Rice author photo is by Nora Green. 